\title{
Histone deacetylase 7 inhibits plakoglobin expression to promote lung cancer cell growth and metastasis
}

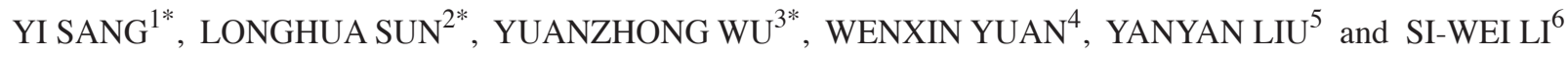 \\ ${ }^{1}$ Jiangxi Key Laboratory of Cancer Metastasis and Precision Treatment, Department of Center Laboratory, \\ The Third Affiliated Hospital of Nanchang University; ${ }^{2}$ Department of Respiratory, The First Affiliated Hospital of \\ Nanchang University, Nanchang, Jiangxi 330008; ${ }^{3}$ State Key Laboratory of Oncology in South China, Collaborative \\ Innovation Center for Cancer Medicine, Sun Yat-Sen University Cancer Center, Guangzhou, Guangdong 510060; \\ ${ }^{4}$ Department of Ultrasonography, The First Affiliated Hospital, Nanchang University, Nanchang, Jiangxi 330008; \\ ${ }^{5}$ Department of Nephrology, Tongji Hospital, Tongji Medical College, Huazhong University of Science and Technology, \\ Wuhan, Hubei 430030; ${ }^{6}$ Department of Radiation Oncology, Hubei Cancer Hospital, Wuhan, Hubei 430079, P.R. China
}

Received May 30, 2018; Accepted December 6, 2018

DOI: 10.3892/ijo.2019.4682

\begin{abstract}
Plakoglobin is a tumor suppressor gene in lung cancer; however, the mechanism by which it is downregulated in lung cancer is largely unknown. The aim of the present study was to investigate whether histone deacetylases (HDACs) regulate plakoglobin expression in lung cancer. The effects of overexpression or knockdown of HDAC7 on plakoglobin were determined using stably transfected lung cancer cell lines. Chromatin immunoprecipitation assays were performed to elucidate the mechanisms underlying the HDAC7-induced suppression of plakoglobin. A Cell Counting Kit-8 and Transwell assays were performed, and a nude mouse in vivo model was established to investigate the role of the HDAC7/plakoglobin pathway in cell migration, invasion and metastasis. Ectopic expression of HDAC7 was identified to suppress mRNA and protein levels of plakoglobin in lung cancer cells, whereas silencing HDAC7 with short hairpin RNA increased the expression of plakoglobin. HDAC7 was proposed to suppressed plakoglobin by directly binding to its promoter. Overexpression or knockdown of HDAC7 promoted or inhibited cell proliferation, migration and invasion, respectively. Furthermore, knockdown of HDAC7 significantly
\end{abstract}

Correspondence to: Professor Si-Wei Li, Department of Radiation Oncology, Hubei Cancer Hospital, 116 Zhuodaoquan South Road, Hongshan, Wuhan, Hubei 430079, P.R. China

E-mail: 1272601449@qq.com

Professor Yanyan Liu, Department of Nephrology, Tongji Hospital, Tongji Medical College, Huazhong University of Science and Technology, 1095 Jie Fang Avenue, Hankou, Wuhan 430030, P.R. China E-mail: liuyy1919@163.com

*Contributed equally

Key words: histone deacetylase 7, plakoglobin, lung cancer, tumor growth and metastasis suppressed tumor growth and metastasis in vivo. In addition, overexpression of plakoglobin significantly reduced the enhanced cell proliferation, migration and invasion induced by ectopic HDAC7. In conclusion, suppression of plakoglobin by HDAC7 promoted the proliferation, migration, invasion and metastasis in lung cancer. This novel axis of HDAC7/ plakoglobin may be valuable in the development of novel therapeutic strategies for treating patients with lung cancer.

\section{Introduction}

Lung cancer is the leading cause of cancer-associated mortality worldwide $(1,2)$, with an associated 5-year survival rate of $<16 \%$ (3). Advancements in treatment have been made recently (4); however, the molecular mechanisms underlying the pathogenesis of lung cancer remain unknown. Therefore, there is an urgent requirement to identify the molecular mechanisms underlying lung cancer in order to develop novel treatment strategies and improve patient survival.

Plakoglobin is a member of the armadillo family of proteins, and is a structural and functional homolog of $\beta$-catenin (5-7). Notably, previous studies have reported that a decreased level of plakoglobin is associated with shorter disease-free survival (DFS) and worse overall survival (OS) in non-small cell lung cancer (NSCLC) (8-10). On the contrary, He et al (11) demonstrated that high cytoplasmic plakoglobin expression in tumor tissues is associated with poor DFS and OS in patients with resected lung adenocarcinoma. Unlike $\beta$-catenin, which has an oncogenic function, plakoglobin generally acts as a tumor/metastasis suppressor $(12,13)$. Plakoglobin is weakly expressed in numerous NSCLC cell lines and overexpression of plakoglobin in these cell lines has been demonstrated to inhibit the proliferation of lung cancer cells (14). Overexpressing plakoglobin in SCC-9 squamous carcinoma cells was observed to induce a mesenchymal to epidermoid phenotypic transition (15). Decreased expression of plakoglobin is regulated by promoter hypermethylation in renal cell carcinoma (16), prostate cancer (17), embryonal 
rhabdomyosarcoma (18) and mammary carcinoma (19); however, the factors affecting low plakoglobin expression are largely unknown, and whether plakoglobin is involved in other signaling pathways in lung cancer remains unclear.

Aberrant expression of histone deacetylases (HDACs) is a hallmark of numerous types of cancer, and is involved in mediating the proliferation, migration, invasion and genotoxic chemotherapy resistance of cancer cells (20). HDACs are potential anticancer drug targets that may be used to treat patients with lung cancer $(21,22)$. HDACs act as transcriptional repressors by interacting with corepressor complexes and regulating the acetylation state of histones, resulting in condensed chromatin (23). Plakoglobin regulates HDAC4 expression by binding to its promoter via interactions with the T-cell factor/ lymphoid enhancer-binding factor family of transcription factors (24). Plakoglobin expression is reduced in tumor tissues compared with in normal tissues, and HDACs have been demonstrated to inhibit plakoglobin expression in cancers $(25,26)$; however, which HDACs directly inhibit plakoglobin expression in lung cancer require further investigation.

In the present study, the role of HDACs in regulating plakoglobin expression in lung cancer was investigated. HDAC7 was demonstrated to directly bind to the promoter of plakoglobin to deacetylate $\mathrm{H} 3 \mathrm{~K} 9$ and H4K5 and inhibit plakoglobin expression in lung cancer. This novel HDAC7/ plakoglobin axis may serve as a promising target for treating patients with lung cancer.

\section{Materials and methods}

Cells and reagents. A total of three human lung cancer cell lines (H460, H1299 and A549) were purchased from the American Type Culture Collection (ATCC, Manassas, VA, USA) and were cultured in Dulbecco's modified Eagle's medium (DMEM; cat. no. 11965-092) supplemented with $10 \%$ fetal bovine serum (FBS) (cat. no. 10270-106) (both from Gibco; Thermo Fisher Scientific, Inc., Waltham, MA, USA) and maintained at $37^{\circ} \mathrm{C}$ in an incubator containing $5 \% \mathrm{CO}_{2}$. Dimethyl sulfoxide, Trichostatin A (TSA) and nicotinamide (NAM) were purchased from Sigma-Aldrich (Merck KGaA, Darmstadt, Germany), and $7.5 \mathrm{mM}$ NAM or $0.5 \mathrm{nM}$ TSA was applied to A549, $\mathrm{H} 1299$ or $\mathrm{H} 460$ cells for $24 \mathrm{~h}$ at $37^{\circ} \mathrm{C}$ in an incubator containing $5 \% \mathrm{CO}_{2}$.

Plasmids. The full-length cDNA of human HDAC7 and plakoglobin were cloned into the pSin-puro vector (Focus Bioscience Co., Ltd., Nanchang, China), and the restriction sites were EcoRI and NheI. The full-length cDNA of human HDAC (1-11) was constructed by inserting a Flag tag into the HDAC N-terminus in a pcDNA3.1(+) vector (cat. no. V790-20, Invitrogen; Thermo Fisher Scientific, Inc.) and the plasmids were transfected into H460 cells using Lipofectamine 2000 (no. 11668019; Thermo Fisher Scientific, Inc.). All recombinant plasmids were verified by DNA sequencing (Ruiboxingke Biotech Co., Ltd., Beijing, China).

Antibodies.Human anti-plakoglobin (cat.no. 75550), anti-GAPDH (cat. no. 5174), anti-HDAC7 (cat. no. 33418), anti-Flag (cat. no. 14793) and the Acetyl-Histone Antibody Sampler kits containing anti-H3K9, -H3K18, -H3K27 and -histone 3 (cat. nos. 9927), and anti-H4K5, H4K12, histone 4 (cat. no. 8346) were obtained from Cell Signaling Technology, Inc. (Danvers, MA, USA). Anti- $\beta$-actin (cat. no. 66009-1-1g) was procured from ProteinTech Group, Inc. (Chicago, IL, USA).

Stable lines. H1299 cells stably expressing scrambled (Scr) or HDAC7 short hairpin RNA (shRNA) were established using the Sigma-Aldrich shRNA system (Merck KGaA), according to the manufacturer's protocols. Scr shRNA (with no known targets in the human genome) with the following sequence: 5'-GGGCGAGGAGCTGTTCACCG-3', and the oligonucleotides for human HDAC7 shRNA\#1 and \#2 were 5'-GATCCG GGTGCAAGTAAATA-3' and 5'-CCACTATTCCTGGCT CTGCAA-3', respectively. A total of $3 \mu \mathrm{g}$ pSin-puro delivering HDAC7 or plakoglobin, $3 \mu \mathrm{g}$ pSin-puro-empty vector, $3 \mu \mathrm{g}$ shRNA-NC, $3 \mu \mathrm{g}$ shRNA-HDAC7\#1 or \#2 was co-transfected with $3 \mu \mathrm{g}$ pMD2.G and $3 \mu \mathrm{g}$ psPAX2 into 293 cells (ATCC) for 48 h. using Lipofectamine 2000. The recombinant viruses were subsequently collected and applied to H1299, A549 or H460 cells cultured with $8 \mu \mathrm{g} / \mathrm{ml}$ Polybrene for $24 \mathrm{~h}$. The stable lines were selected with $1 \mu \mathrm{g} / \mathrm{ml}$ puromycin for 2 weeks.

RNA extraction and reverse transcription-quantitative polymerase chain reaction $(R T-q P C R)$. RT-qPCR was performed as described (27). Briefly, total RNA obtained from cell lines was isolated using TRIzol ${ }^{\circledR}$ reagent (Invitrogen; Thermo Fisher Scientific, Inc.) according to the manufacturer's protocols. First-strand cDNA was synthesized at $42^{\circ} \mathrm{C}$ for 60 min using the Revert Aid $^{\mathrm{TM}}$ First Strand cDNA Synthesis kit (cat. no. 6110A; Takara Bio, Inc., Otsu, Japan). Subsequently, the qPCR reaction was performed in a CFX96 Real-Time PCR Detection system (Bio-Rad Laboratories, Inc., Hercules, CA, USA) using SYBR ${ }^{\circledR}$-Green mix (Tiangen Biotech Co., Ltd., Beijing, China). Thermal cycling of the qPCR reaction was initiated with a denaturation step at $95^{\circ} \mathrm{C}$ for $15 \mathrm{~min}$, and consisted of 40 cycles (denaturation at $95^{\circ} \mathrm{C}$ $15 \mathrm{sec}$, annealing at $60^{\circ} \mathrm{C}$ for $30 \mathrm{sec}$ and elongation at $72^{\circ} \mathrm{C}$ for $30 \mathrm{sec}$ ). The amplified products were examined using the $2^{-\Delta \Delta \mathrm{Cq}}$ method (28), and each sample was calibrated to the expression levels of the housekeeping gene GAPDH. The primers used for amplifying HDAC7, plakoglobin and GAPDH were as follows: HDAC7, forward, 5'-GGCGGCCCTAGAAAGAACAG-3' and reverse, 5'-CTTGGGCTTATAGCGCAGCTT-3'; plakoglobin, forward, 5'-TCTCCAACCTGACATGCAACA-3' and reverse, 5'-CATAGTTGAGACGCACAGAGTTC-3'; and GAPDH, forward, 5'-ACAGTCAGCCGCATCTTCTT-3' and reverse, 5'-GACAAGCTTCCCGTTCTCAG-3'.

Cell proliferation assay. In vitro cell proliferation was assessed using the Cell Counting Kit-8 (CCK-8) assay. For cell proliferation, cells were seeded in 96-well plates at a density of 1,000 cells/well and incubated for $1,2,3,4$ or 5 days; $10 \mu \mathrm{l}$ of CCK-8 reagent (Beyotime Institute of Biotechnology, Haimen, China) was then added to each well, followed by incubation for $1.5 \mathrm{~h}$ at $37^{\circ} \mathrm{C}$. The absorbance value (optical density) of each well was measured at $450 \mathrm{~nm}$ using an iMark microplate reader (Bio-Rad Laboratories, Inc.).

Chromatin immunoprecipitation (ChIP) assay. The ChIP assay was performed using the ChIP kit (cat. no. 53008, Active Motif, 
Carlsbad, CA, USA) as described previously (29). Briefly, to fix the cells, Complete Cell Fixative Solution (included in kit) was added to the existing culture medium for the cells at $80 \%$ confluence at room temperature, and the fixation reaction was stopped by adding Stop Solution (included in kit) to the existing culture medium. The cells were collected by centrifugation at $1,000 \mathrm{x} \mathrm{g}$ for $5 \mathrm{~min}$ at $4^{\circ} \mathrm{C}$. Subsequently, the nuclear pellet was resuspended in ChIP Buffer (included in kit). The cell lysate was subjected to shearing using a sonication instrument (Ningbo Scientz Biotechnology Co., Ltd., Ningbo, China) to a fragment length of 200-500 bp. Total genomic DNA (input) was quantified and $20 \mu \mathrm{g}$ of chromatin from each sample was immunoprecipitated overnight at $4^{\circ} \mathrm{C}$ with $5 \mu \mathrm{g}$ anti-HDAC 7 (cat. no. 33418; Cell Signaling Technology, Inc.), anti-acetyl-H3K9 (cat. no. 39917) or anti-acetyl-H4K5 (cat. no. 39699) (both from Active Motif), or normal $\mathrm{IgG}$ as a negative control. Then, nucleosome complexes were isolated with the protein $\mathrm{G}$ agarose beads for $3 \mathrm{~h}$ at $4^{\circ} \mathrm{C}$. Bound DNA-protein complexes were eluted and cross-links were reversed after a series of washes using the washing reagent contain in the ChIP kit. Purified DNA was resuspended in TE buffer. Subsequently, the PCR reaction was performed using PrimeSTAR ${ }^{\circledR}$ Max DNA Polymerase (cat. no. R045A; Takara Bio, Inc.). Thermal cycling of the qPCR reaction was initiated with a denaturation step at $94^{\circ} \mathrm{C}$ for $2 \mathrm{~min}$, and consisted of 35 cycles (denaturation at $98^{\circ} \mathrm{C} 10 \mathrm{sec}$, annealing at $60^{\circ} \mathrm{C}$ for $15 \mathrm{sec}$ and elongation at $72^{\circ} \mathrm{C}$ for $30 \mathrm{sec}$ ). The primers for the plakoglobin were as follows: Plakoglobin-ChIP, forward, 5'-GGACAGTCAGGCGAGATAGC-3' and reverse, 5'-CGAACAAAAGGCGAAGAGAC-3'

Transwell assays. For the Transwell migration assay, 4.0x10 (A549) or $1.5 \times 10^{5}$ (H1299) cells in $200 \mu 1$ serum-free DMEM were added to cell culture inserts with an $8-\mu \mathrm{m}$ microporous filter, without an extracellular matrix coating (BD Biosciences, Franklin Lakes, NJ, USA). DMEM medium containing 10\% FBS (Gibco; Thermo Fisher Scientific, Inc.; cat. no. 10270-106) was then added to the bottom chamber. After $24 \mathrm{~h}$ of incubation at $37^{\circ} \mathrm{C}$ in an incubator containing $5 \% \mathrm{CO}_{2}$, the cells on the lower surface of the filter were fixed, stained and examined under a light microscope. The number of migrated cells in three random optical fields (magnification, x10) from triplicate filters was averaged. For the Transwell invasion

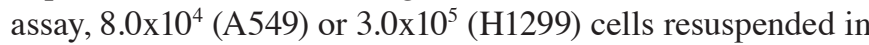
$200 \mu \mathrm{l}$ serum-free DMEM were added to cell culture inserts, which contained 8- $\mu \mathrm{m}$ microporous filters and were coated with Matrigel (BD Biosciences; cat. no. 354480). DMEM containing $10 \%$ FBS was then added to the bottom chamber. After $24 \mathrm{~h}$ of incubation at $37^{\circ} \mathrm{C}$ in an incubator containing $5 \% \mathrm{CO}_{2}$, the cells on the lower surface of the filter were fixed with $10 \%$ formalin for $15 \mathrm{~min}$ at room temperature, stained with $0.1 \%$ crystal violet for $60 \mathrm{~min}$ at room temperature and examined under a light microscope. The number of migrated cells in three random optical fields (magnification, x100) from triplicate filters was averaged.

Western blotting. Western blotting procedures were performed as described previously (3), including the experimental conditions of the gels. Briefly, cultured cells from all cell lines were lysed in ice-cold radioimmunoprecipitation assay lysis buffer (cat. no. P0013C; Beyotime Institute of Biotechnology) at $4^{\circ} \mathrm{C}$ for $30 \mathrm{~min}$. Following centrifugation $(12,000 \mathrm{x} \mathrm{g})$ at $4^{\circ} \mathrm{C}$ for $20 \mathrm{~min}$, the lysates were obtained and protein concentration was determined with the BCA method. Equal amounts of protein $(30 \mu \mathrm{g} /$ lane) were separated by $10 \%$ SDS-PAGE. The conditions were as follows: Voltage of $100 \mathrm{~V}$ for $2.5 \mathrm{~h}$ at room temperature. Proteins were then transferred to polyvinylidene fluoride membranes with an electrical current of $250 \mathrm{~mA}$ at $4^{\circ} \mathrm{C}$ for $2 \mathrm{~h}$. To block the non-specific binding sites, the membranes were incubated with $5 \%$ non-fat milk (in Tris-buffered saline with $0.1 \%$ Tween-20) at room temperature for $60 \mathrm{~min}$, and then membranes were then incubated with the following primary antibodies: Human anti-plakoglobin (cat. no. 75550, anti-GAPDH (cat. no. 5174), anti-HDAC7 (cat. no. 33418), anti-Flag (cat. no. 14793) and the Acetyl-Histone Antibody Sampler kit (cat. nos. 9927 and 8346) (all from Cell signaling Technology, Inc.), anti- $\beta$-actin (cat. no. 66009-1-1g; ProteinTech Group, Inc.) at a dilution of 1:1,000 overnight at $4^{\circ} \mathrm{C}$. Subsequently, the membranes were incubated with anti-rabbit IgG Secondary antibody peroxidase-conjugated (cat. no. W401B; Promega Corporation, Madison, WI, USA) and anti-Mouse IgG Secondary Antibody Peroxidase Conjugated (cat. no. W402B; Promega Corporation) with the dilution 1:10,000 at room temperature for $2 \mathrm{~h}$. Specific protein bands were visualized using an enhanced chemiluminescence detection system (cat. no. P0018F; Beyotime Institute of Biotechnology) and exposed to radiographic film (Carestream Health, Rochester, NY, USA; cat. no. 6535876).

Animal experiments. All animal studies were performed in accordance with protocols approved by the Research Animal Resource Center of Sun Yat-Sen University (Guangzhou, China). The mice were maintained in specific pathogen free conditions at a temperature of $20-25^{\circ} \mathrm{C}$, a $50-70 \%$ humidity, under a light/dark cycle of $12 \mathrm{~h}$, with free access to water and food. A total of 18 male athymic nude mice at 4 weeks of age were obtained from Shanghai Institutes for Biological Sciences, Chinese Academy of Sciences (Shanghai, China). For subcutaneous injection, 2x10 ${ }^{6} \mathrm{H} 1299$ cells with stably expressing Scr or shHDAC7-1 were mixed with $0.2 \mathrm{ml}$ PBS ( $\mathrm{pH} 7.4$ ) and 30\% (v/v) Matrigel matrix (BD Biosciences). Suspensions were injected subcutaneously into the flanks of 4-week-old male athymic nude mice, which were monitored over 5 weeks. For tail vein injection, $3 \times 10^{6} \mathrm{H} 1299$ cells with stably expressing Scr or shHDAC7-1 were resuspended in $300 \mu 1$ PBS (Biological Industries, Beit Haemek, Israel) and injected into the lateral tail vein of mice that did not receive a subcutaneous injection of cells $\left(3 \times 10^{6}\right.$ cells/animal). Mice were sacrificed 7 weeks following injection, and nodules were counted and compared between the H1299-scr and H1299-shHDAC7-1 groups.

Immunohistochemistry (IHC) and histological evaluation. Samples were fixed in $10 \%$ formalin for $10 \mathrm{~h}$ at room temperature and embedded in paraffin. Sections $(3-\mu \mathrm{m}$ thick) were prepared and mounted onto positively-charged glass slides. Sections for HDAC7 staining were incubated in $10 \mathrm{mM}$ citrate buffer ( $\mathrm{pH}$ 6.0) and boiled in a microwave oven for $15 \mathrm{~min}$. After incubation with Protein Block Serum-Free (Dako; Agilent Technologies, Inc., Santa Clara, CA, USA), sections were incubated overnight with anti-HDAC7 (1:250) 


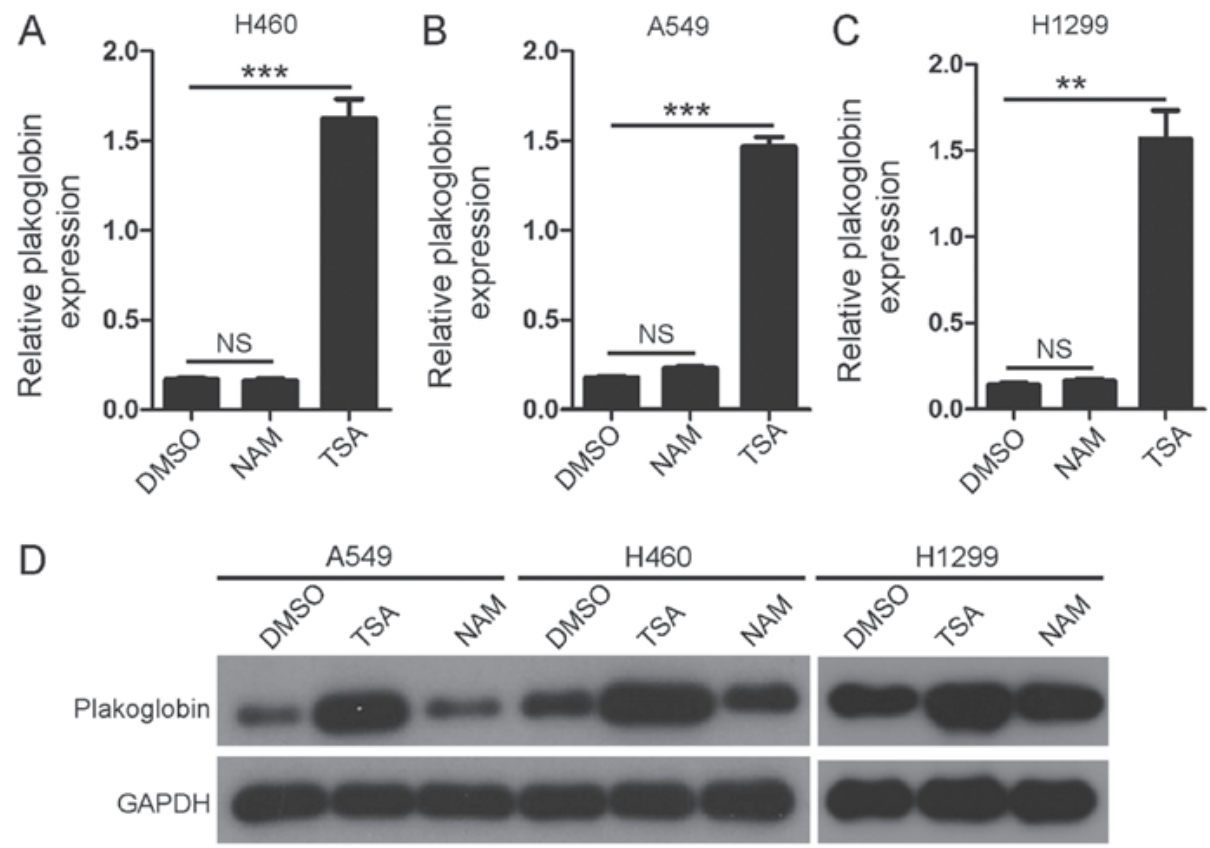

Figure 1. Plakoglobin expression is upregulated following treatment with histone deacetylase inhibitor TSA. (A-C) mRNA expression levels of plakoglobin were determined via reverse transcription-quantitative polymerase chain reaction in H460, A549 and H1299 cells treated with TSA or NAM for $24 \mathrm{~h}$. GAPDH was used as an internal control. Data are presented as the mean \pm standard error $(n=3)$. ${ }^{* *} \mathrm{P}<0.01,{ }^{* * *} \mathrm{P}<0.001$. (D) Protein expression levels of plakoglobin were determined via western blot analysis in H460, A549 and H1299 cells treated with TSA or NAM for 24 h. GAPDH was used as an internal control. DMSO, dimethyl sulfoxide; NAM, nicotinamide; TSA, trichostatin A.

at $4^{\circ} \mathrm{C}$ in a humidified container. Following washing with PBS three times, the tissue slides were treated with a non-biotin horseradish peroxidase detection system according to the manufacturer's protocols (Dako; Agilent Technologies, Inc.). IHC staining was evaluated by two independent pathologists who were experts in diagnosing lung cancer. HDAC7 detection was quantified as described (3). Briefly, the HDAC7 signal was detected in the cytoplasm and the nucleus, and the intensity in tissues was categorized into four categories: 0, absent; 1, weak; 2 , moderate; or 3 , strong. The percentage of stained cells was categorized as: 0 , no staining; $1,1-10 \% ; 2,11-50 \% ; 3,51-80 \%$; and $4,81-100 \%$. The staining score for each tissue was calculated by multiplying the intensity value by the percentage value, and the average of the scores from the two pathologists was used as the final score.

Clinical dataset analysis. The association between HDAC7, and the clinical characteristics or survival of lung cancer patients were analyzed using the online KMplot database (30). The median value of expression was selected as the cutoff in the online database; Cox's proportional hazards model was used to estimate the hazard ratio.

Study approval. A total of 35 pairs of specimens were collected from patients with lung cancer (median age, 45 years; age range, 33-78 years; male/female ratio, 3:4) with resection between March 2014 and September 2016, and inclusion criteria were as follow: Initial diagnosis of lung cancer. Exclusion criteria included: Previous radiotherapy, chemotherapy or surgery, and previous malignancy or other concomitant malignant disease. Normal lung tissues were collected at $>5 \mathrm{~cm}$ from the edge of the tumor. The use of human lung cancer tissues was reviewed and approved by the Ethics Committee of the Sun Yat-Sen
University Cancer Center. Informed consent was obtained from patients.

The correlation between plakoglobin and HDAC7 expression. The raw data for the correlation between plakoglobin and HDAC7 expression were obtained from the MethHC 1.0.3. software (http://methhc.mbc.nctu.edu.tw/php/index.php).

Statistical analysis. All statistical analyses were performed using SPSS for Windows, version 16.0 (SPSS, Inc., Chicago, IL, USA). All values from the in vitro assays were expressed as the mean \pm standard deviation or standard error of the mean of at least three independent experiments or replicates. A paired Student's t-test was used for the comparison of two groups, multiple group comparisons were performed by using one-way analysis of variance followed by a Tukey-Kramer post-hoc test. The correlation between plakoglobin and HDAC7 expression was analyzed by a Pearson's correlation analysis. The Mann-Whitney test was used to analyze the difference expression of HADC7 in lung cancer tissues and paired normal tissues. $\mathrm{P}<0.05$ was considered to indicate a statistically significant difference.

\section{Results}

Treating lung cancer cells with TSA increases the mRNA and protein expression of plakoglobin. H460, A549 and H1299 cells were treated with HDAC inhibitors TSA and NAM for $24 \mathrm{~h}$; these reagents are inhibitors of class I and II HDACs and class III HDACs $(31,32)$, respectively. It was identified that the addition of TSA, but not NAM, significantly increased the mRNA expression levels of plakoglobin compared with the control (Fig. 1A-C); notable increases in the protein expression 
A

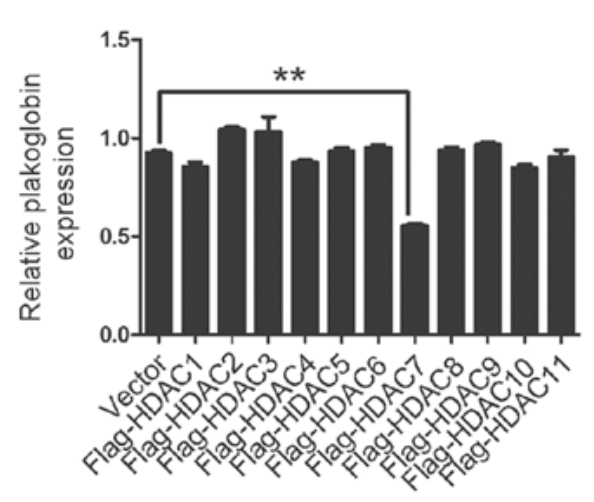

C

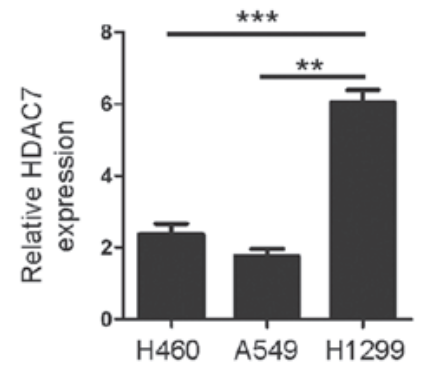

B
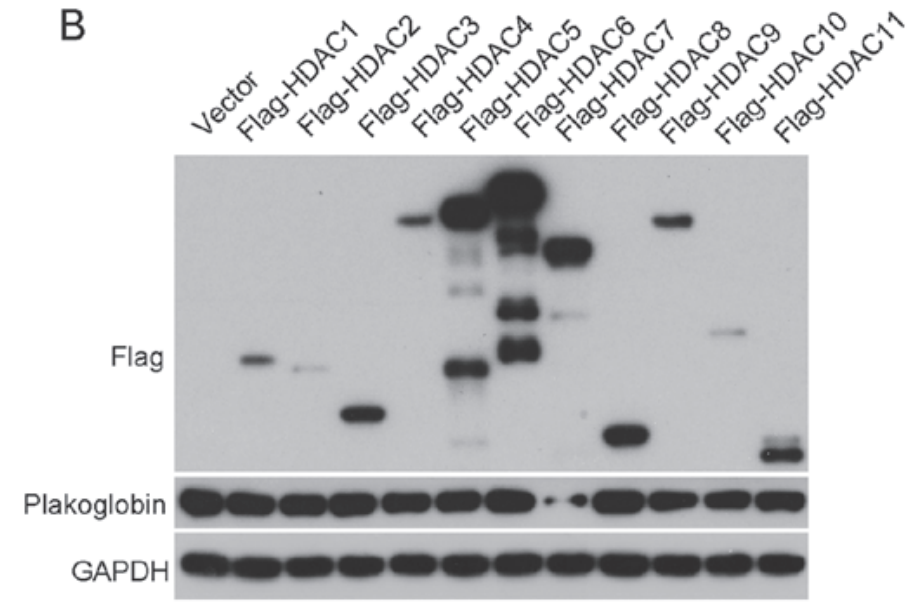
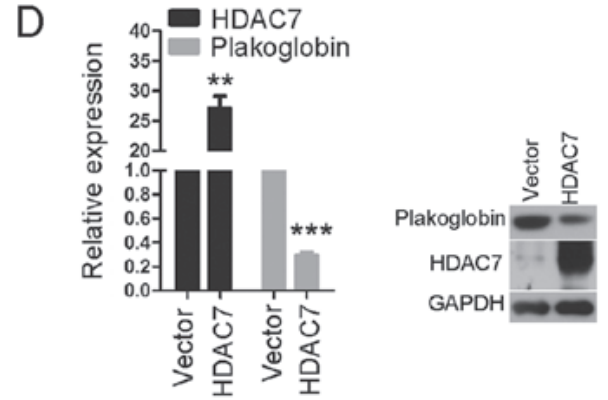

$\mathrm{F}$

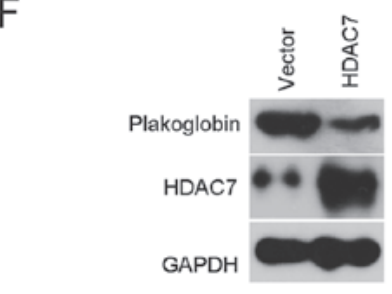

$\mathrm{E}$

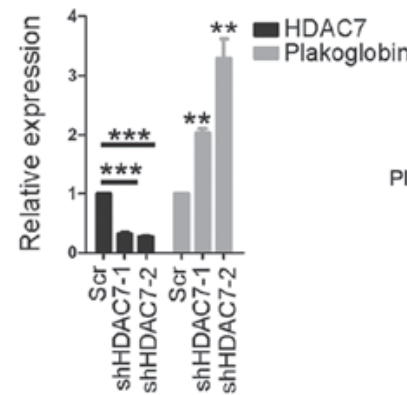

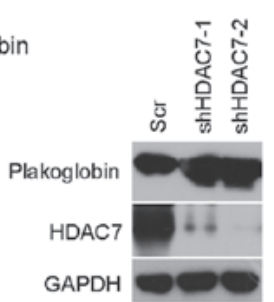

GAPDH

Figure 2. HDAC7 inhibits plakoglobin expression. (A and B) H460 cells were transfected with empty vector or Flag-tagged HDACs, as indicated, for 48 h. (A) mRNA expression levels of plakoglobin were evaluated via RT-qPCR. Data are presented as the mean \pm standard deviation. ${ }^{* *} \mathrm{P}<0.01$. (B) Protein expression levels of plakoglobin and the HDACs were determined via western blotting. (C) mRNA levels of HDAC7 were detected by RT-qPCR. Data are presented as the mean \pm standard deviation. ${ }^{* *} \mathrm{P}<0.01,{ }^{* * *} \mathrm{P}<0.001$. (D) Overexpression of HDAC7 in A549 suppressed the mRNA and protein levels of plakoglobin. ${ }^{* *} \mathrm{P}<0.01,{ }^{* * *} \mathrm{P}<0.001$ vs. vector. (E) Silencing HDAC7 in $\mathrm{H} 1299$ increased the mRNA and protein levels of plakoglobin. Data are presented as the mean \pm standard deviation. ${ }^{* *} \mathrm{P}<0.01,{ }^{* * *} \mathrm{P}<0.001$ vs. Scr. (F) Overexpression of HDAC7 in H1299 suppressed the protein levels of plakoglobin. HDAC, histone deacetylases; RT-qPCR, reverse transcription-quantitative polymerase chain reaction; Scr, scrambled.

levels of plakoglobin were observed following TSA treatment. The results indicated that plakoglobin may be regulated by class I and II HDACs in lung cancer cells.

HDAC7 is a novel negative regulator of plakoglobin in lung cancer. In order to determine which class I and II HDAC was responsible for the suppression of plakoglobin expression, class I and II HDACs were ectopically expressed in lung cancer cells. As presented in Fig. 2A and B, only ectopic HDAC7 significantly suppressed the mRNA levels of plakoglobin in H460 cells; the protein expression levels of HDA7 were notably downregulated. Furthermore, the expression levels of HDAC in three cancer cell lines was determined (Fig. 2C). It was evaluated whether overexpression of HDAC7 could decrease plakoglobin expression in other lung cancer cells according to the endogenous levels of HDAC7 in the H460, H1299 and
A549 cell lines. RT-qPCR indicated that stable expression of HDAC7 significantly suppressed the mRNA expression levels of plakoglobin in A549 cells compared with the control; the protein expression levels of plakoglobin following HDAC7 overexpression were notably reduced(Fig.2D). Thus, plakoglobin expression was downregulated by overexpression of HDAC7. The opposite effect was observed with HDAC7 knockdown in H1299 cells. As indicated in Fig. 2E, the two shRNA sequences effectively decreased the expression of endogenous HDAC7 levels compared with the control, whereas the mRNA and protein expression levels of plakoglobin increased. Furthermore, the protein expression levels of plakoglobin decreased following stable overexpression of HDAC7 in H1299 cells (Fig. 2F).

HDAC7 directly binds to the promoter region of plakoglobin and deacetylates histones $\mathrm{H} 3$ and $\mathrm{H} 4$ in lung cancer. To investigate 
A
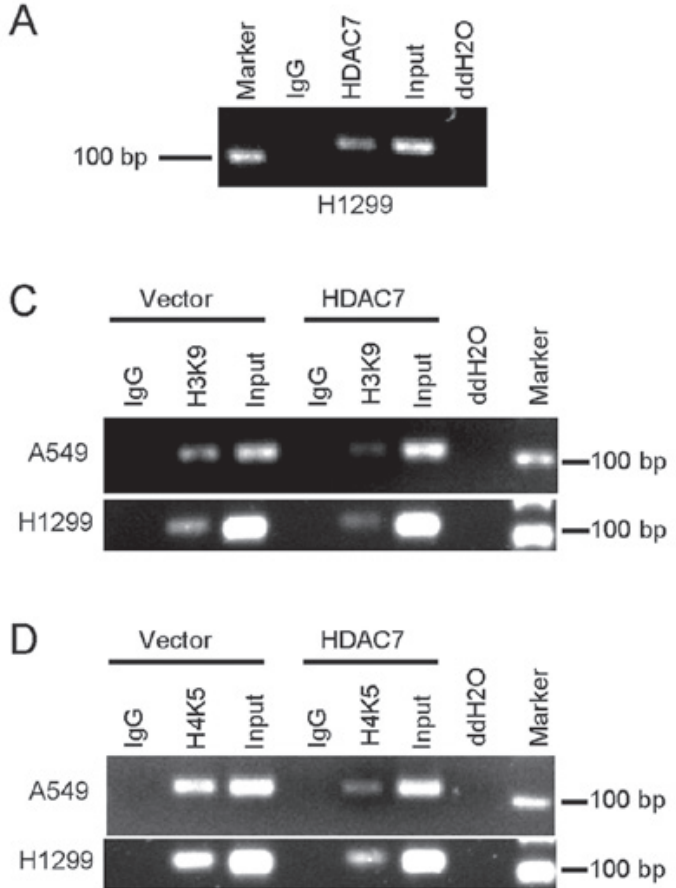

B

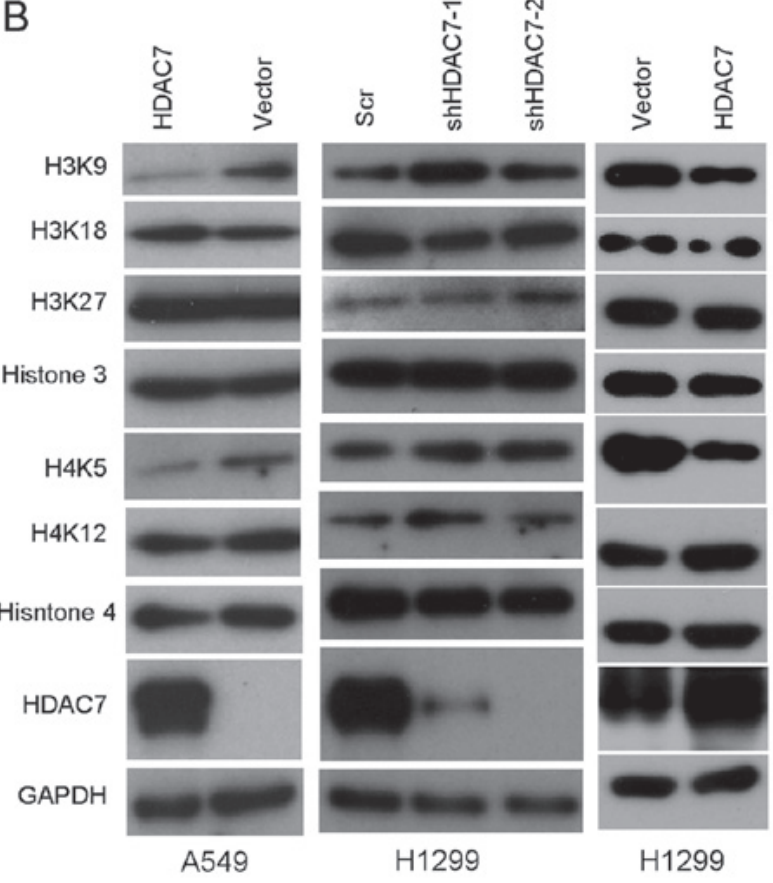

F

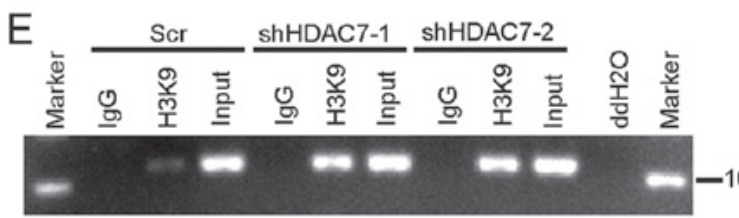

H1299

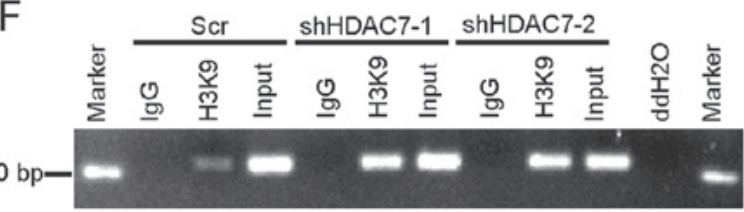

H1299

Figure 3. HDAC7 directly binds to the promoter region of plakoglobin and deacetylases histone $\mathrm{H} 3$ and histone $\mathrm{H} 4$ in lung cancer. (A) ChIP assays in H1299 cells were performed using anti-HDAC7 or negative control IgG. (B) The levels of acetylation at the corresponding residues of histone H3 and H4 were decreased or increased following overexpressing or knockdown, respectively. (C and D) ChIP analysis of the occupancies of $\mathrm{H} 3 \mathrm{~K} 9$ and $\mathrm{H} 4 \mathrm{~K} 5$ on the plakoglobin promoter in stably transfected vector or HDAC7 cells. The levels of H3K9 and H4K5 on the plakoglobin promoter decreased following overexpressing HDAC7 in A549 and H1299 cells. (E and F) ChIP analysis of H3K9 and H4K5 on the plakoglobin promoter in H1299-Scr, H1299-shHDAC 7-1 and H1299-shHDAC7-2 groups. The levels of H3K9 and H4K5 on the plakoglobin promoter increased after knocking down HDAC7 in H1299 cells. HDAC, histone deacetylase; ChIP, chromatin immunoprecipitation; Scr, scrambled; sh, short hairpin RNA.

the mechanisms by which HDAC7 participates in silencing plakoglobin expression, a ChIP assay was performed to analyze whether HDAC7 directly binds to the plakoglobin promoter. The results indicated that HDAC7 binds to the plakoglobin promoter in H1299 cells (Fig. 3A). Acetylation of histones 3 and 4 was assessed by western blot analysis using antibodies targeting lysine residues that are known to be acetylated. It was identified that the levels of acetylation at $\mathrm{H} 3 \mathrm{~K} 9$ and $\mathrm{H} 4 \mathrm{~K} 5$ markedly increased following knockdown of HDAC7 with shDAC7 \#2 in H1299 cells compared with the control (Fig. 3B); however, overexpression of HDAC7 decreased the levels of the H3K9 and H4K5 acetylation in A549 and H1299 cells (Fig. 3B). To investigate whether $\mathrm{H} 3 \mathrm{~K} 9$ and H4K5 acetylation was decreased in the promoter of plakoglobin, a ChIP assay was performed to analyze H3K9 and H4K5 acetylation within the plakoglobin promoter regions. The results indicated that the degree of histone acetylation at this promoter was decreased in HDAC7-overexpressing A549 and H1299 cells (Fig. 3C and D). By contrast, the level of histone acetylation at this promoter increased in HDAC7-knocked down H1299 cells (Fig. 3E and F). Acetylation of H3K9 and H4K 5 contributes to chromatin decondensation (33), and the enrichment of acetylated H3K9 and H4K5 near a transcription initiation site is associated with the transcriptional activity of the gene $(33,34)$. Thus, HDAC7 may directly inhibit the transcription of plakoglobin via binding to the promoter region of plakoglobin and deacetylating histones $\mathrm{H} 3 \mathrm{~K} 9$ and $\mathrm{H} 4 \mathrm{~K} 5$ in lung cancer.

HDAC7 expression is increased in lung cancer samples and higher HDAC7 levels predict a poor outcome. As plakoglobin is downregulated in lung cancer tissues (9), the expression of HDAC7 in lung cancer tissues was evaluated using IHC. The results indicated that HDAC7 expression significantly increased in lung cancer tissues compared with paired normal tissues (Fig. 4A); representative images were presented (Fig. 4B). Using an online database (35), an inverse correlation was identified between HDAC7 and plakoglobin in tissues (Fig. 4C). In addition, whether the mRNA expression levels of HDAC7 is clinically relevant in lung cancer was determined in the present study. Based on the HDAC7 mRNA levels, lung cancer samples were subdivided into two groups, and the associated OS was analyzed. Individuals with high HDAC7 levels were observed to exhibit shorter OS compared with those with low levels (Fig. 4D) using a large public clinical microarray database of lung tumors from 2,170 patients (30). Therefore, HDAC7 expression levels may be a clinical predictor in lung cancer. 

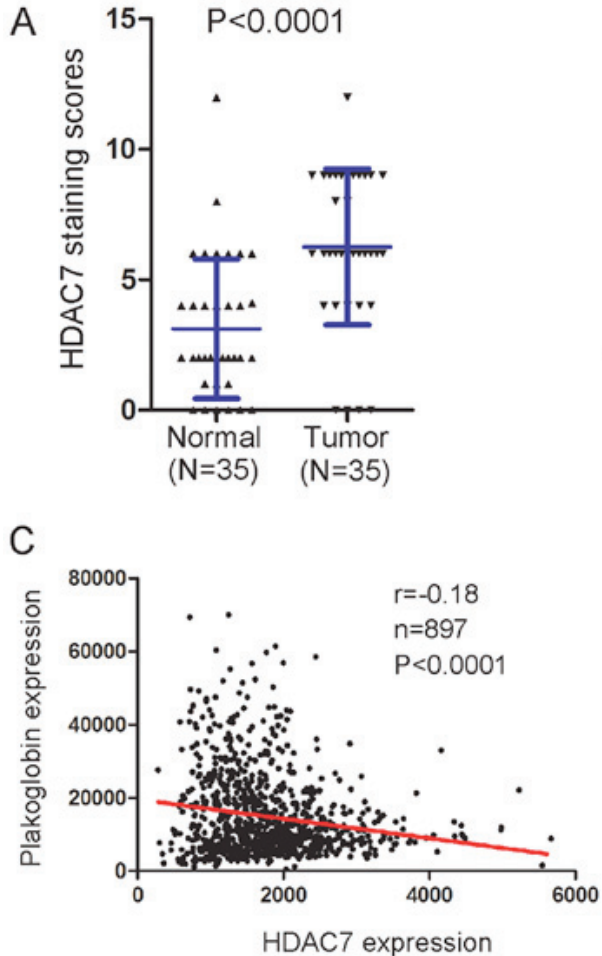
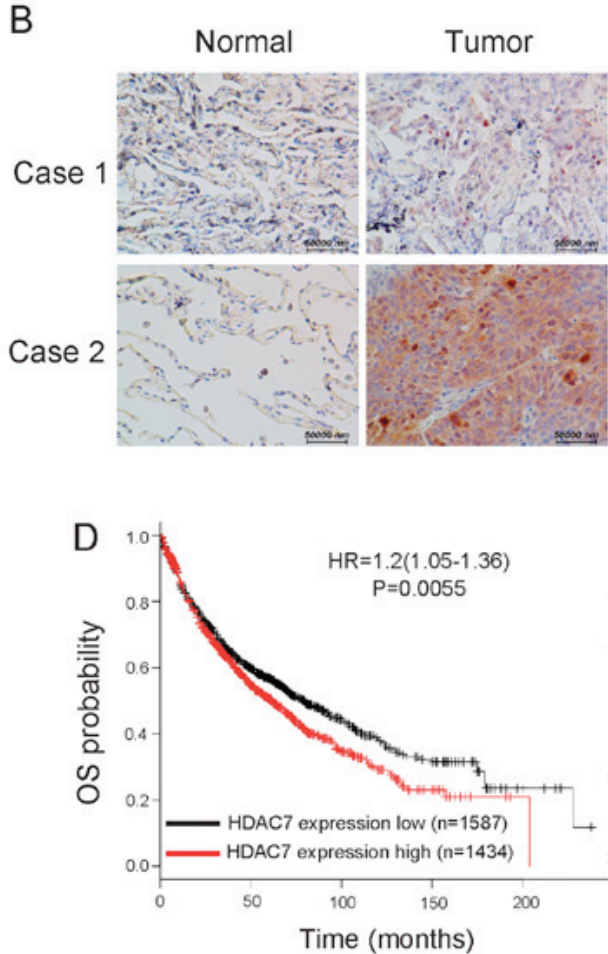

Figure 4. HDAC7 expression is increased in lung cancer samples and higher HDAC7 levels predict a poor outcome. (A and B) Immunohistochemical analysis lung cancer tissues $(n=35)$ and paired normal tissues $(n=35)$. Panel B presents representative images, and panel A comprises the statistical results based on a Mann-Whitney test. The dots represent the scores, and the bars indicate the standard deviation. Scale bar, $50 \mu \mathrm{m}$. (C) A negative correlation between HDAC7 expression and plakoglobin expression was observed in the lung cancer tissues. $\mathrm{r}$ is a measure of the linear correlation between two variables HDAC7 expression and plakoglobin expression; $r=-0.18$ stands for a negative correlation between HDAC7 expression and plakoglobin expression in lung cancer tissues. The correlation between plakoglobin and HDAC7 expression was analyzed by a Pearson's correlation analysis. The raw data were obtained from the MethHC database. (D) Lung cancer patients with higher HDAC7 expression exhibited significantly shorter OS compared with those with low expression ( $\mathrm{P}=0.0055$ ). Cox's proportional hazards model was used to estimate HR. HR $>1$ indicates that the patients with high HDAC7 expression exhibited a poor prognosis. HDAC, histone deacetylase; HR, hazard ratio; OS, overall survival.

HDAC7 promotes lung cancer growth and metastasis. Subsequently, it was investigated whether HDAC7 regulates the biological behaviors of lung cancer cells. Stable cell lines with either ectopic expression of HDAC7 in A549 and H1299 cells, or silenced HDAC7 in H1299 cells, were constructed (Fig. 2C-E). Cell proliferation assays indicated that the ectopic expression of HDAC7 significantly promoted cell proliferation of A549 cells compared with the control (Fig. 5A). The migration and invasion of lung cancer cells was analyzed. The ectopic expression of HDAC7 significantly enhanced cell migration and invasion abilities of A549 cells compared with the control (Fig. 5B and C). The proliferative ability was notably increased following HDAC7 overexpression in H1299 cells (Fig. 5D); however, significant increases in migration and invasion were observed compared with the control (Fig. 5E and F). On the contrary, knockdown of HDAC7 markedly reduced cell proliferation (Fig. 5G), and significantly inhibited H1299 cell migration and invasion compared with the control (Fig. 5H and I). In summary, these findings indicate that HDAC7 promotes lung cancer cell proliferation, migration and invasion.

As HDAC7 was observed to promote lung cancer cell proliferation, migration and invasion in vitro, whether HDAC7 promotes lung cancer cell tumorigenesis and metastasis was investigated in vivo. To confirm the promoting effects of HDAC7, an in vivo tumorigenesis study was performed by inoculating shHDAC7 H1299 cells into nude mice. Mice in the shHDAC7\#1-H1299 and Scr groups were sacrificed 5 weeks after inoculation, with average tumor weights of 0.04 and $1.313 \mathrm{~g}$, respectively $(\mathrm{P}<0.01$; Fig. 5J-L). These results suggested a significant inhibitory effect of decreased HDAC7 on in vivo tumorigenesis.

To further evaluate the role of HDAC7 in lung cancer cell migration and invasion in vivo, lung cancer cells with or without HDAC7 knockdown were injected into nude mice via the tail vein. Cells with endogenous HDAC7 formed colonies in the lungs within 7 weeks of injection, whereas the HDAC7 knockdown cells resulted in significantly reduced pulmonary metastatic colonization ability (Fig. 5M and N). These results suggest that HDAC7 promotes lung tumor growth and metastasis in vivo.

Suppression of plakoglobin by HDAC7 promotes cell proliferation, migration and invasion in lung cancer. As the aforementioned experiments demonstrated that plakoglobin was a direct target of HDAC7, whether loss of plakoglobin contributes to the oncogenic role of HDAC7 in lung cancer was determined. Plakoglobin was stably induced into HDAC7-overexpressing lung cancer cells to observe whether restoration of plakoglobin expression could rescue the promoted cell proliferation, migration and invasion of HDAC7-overexpressing cells in vitro (Fig. 6A). Notably, overexpression of plakoglobin significantly reduced the effects of HDAC7 overexpression on cell proliferation, migration and 

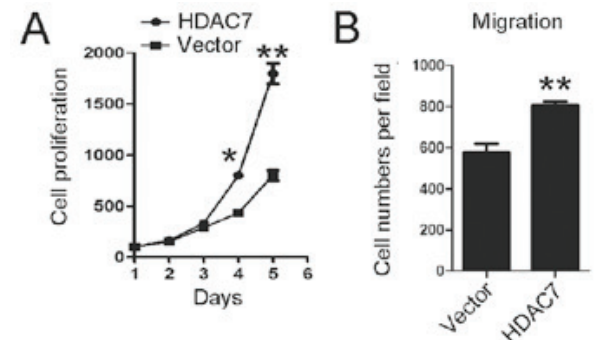

$E$
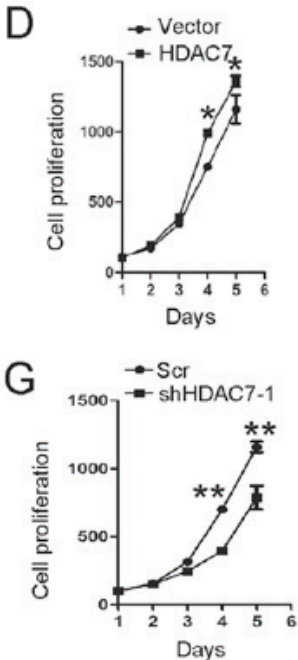

$\mathrm{H}$
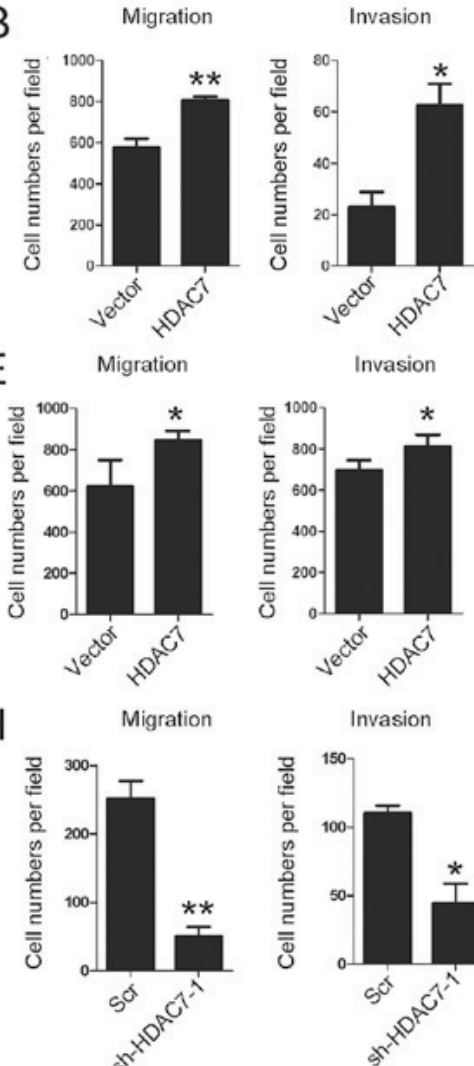

C

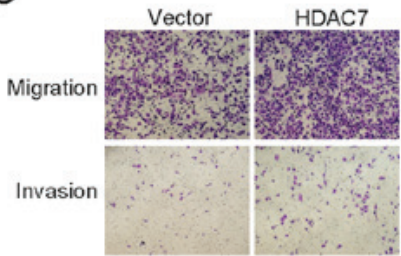

$\mathrm{F}$
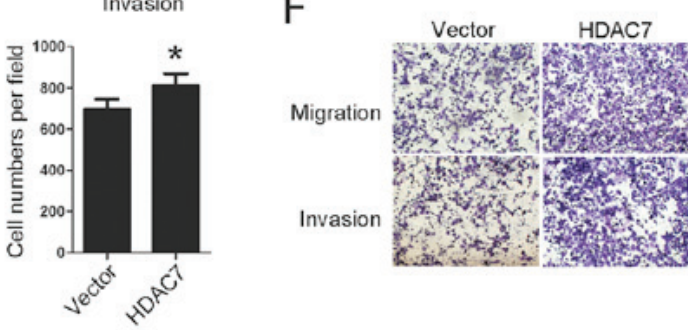

I
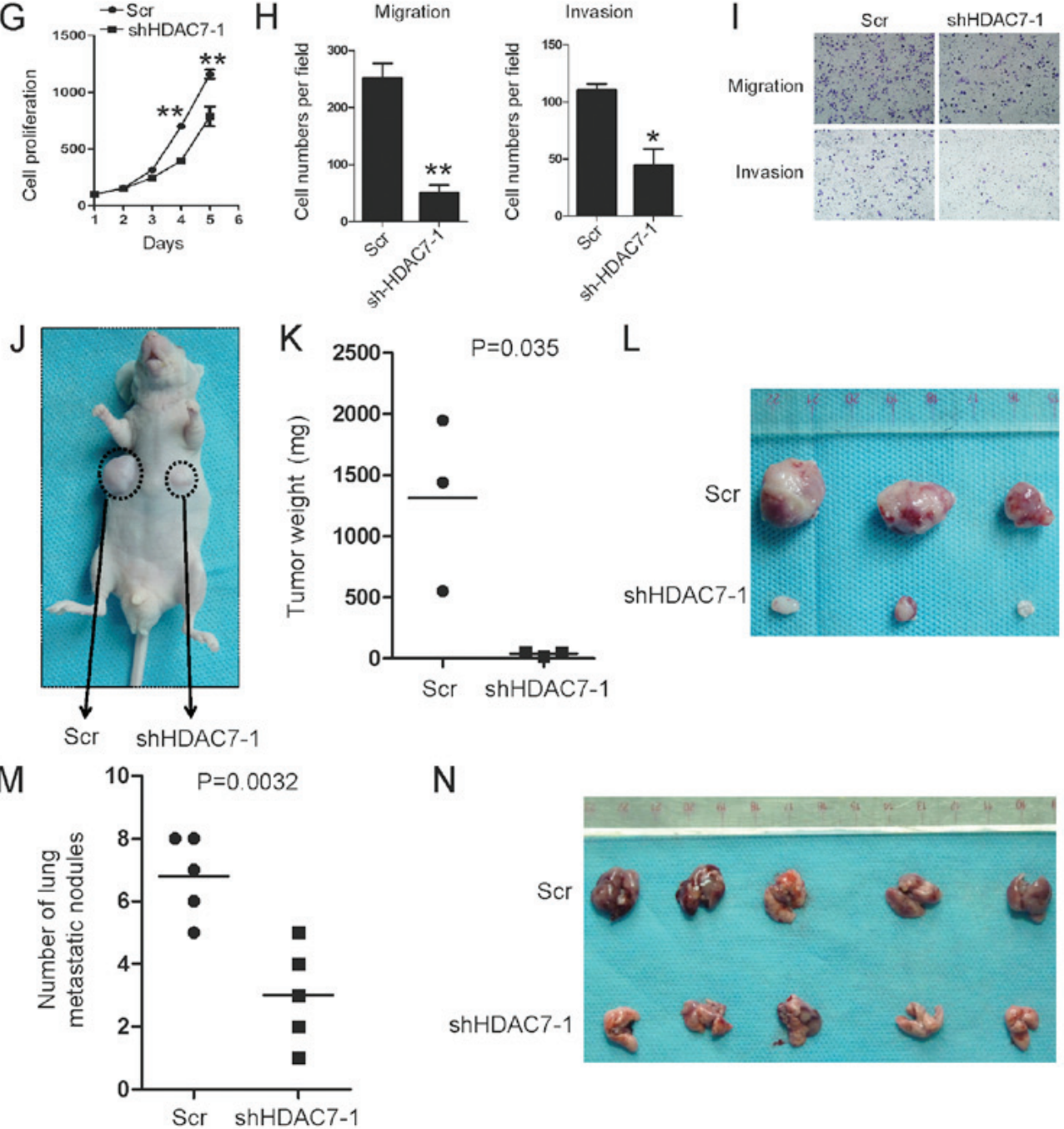

$\mathrm{N}$

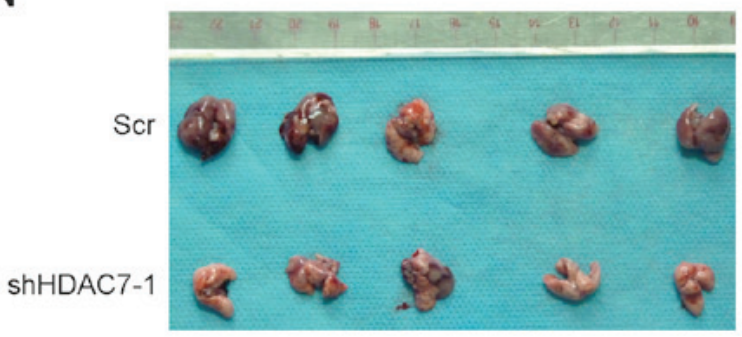

Figure 5. HDAC7 promotes tumor growth and metastasis. (A and D) Cell proliferation of A549 and H1299 cells transfected with HDAC7-overexpressing or empty vector in vitro was measured at different time-points, as indicated by a CCK- 8 assay. Data are presented as the mean \pm standard error. "P $<0.05$, ${ }^{* *} \mathrm{P}<0.01$ vs. Vector. The migration and invasion abilities of (B and C) A549 and (E and F) H1299 cells transfected with HDAC7-overexpressing or empty vector were measured at $24 \mathrm{~h}$ by Transwell assays. Data are presented as the mean \pm standard deviation. ${ }^{*} \mathrm{P}<0.05,{ }^{* *} \mathrm{P}<0.01$ vs. Vector .The number of cells passing via the membrane in each cell was statistically analyzed in triplicate and repeated three times with similar results. Magnification, x100. (C) and (F) are representative images. (G) Cell proliferation of H1299 cells expressing sh-HDAC7-1 or Scr in vitro was measured at different time-points, as indicated by a CCK-8 assay. Data are presented as the mean \pm standard error. ${ }^{* *} \mathrm{P}<0.01$ vs. Scr. (H and I) Cell migration and invasive abilities of H1299 cells expressing sh-HDAC7-1 and Scr were measured at $24 \mathrm{~h}$ by Transwell assays. Data are presented as the mean \pm standard deviation. ${ }^{*} \mathrm{P}<0.05,{ }^{* *} \mathrm{P}<0.01$ vs. Scr. The number of cells passing via the membrane in each cell was statistically analyzed in triplicate and repeated three times with similar results. (I) Is a representative image. (J-L) Stable H1299 with HDAC7 knockdown cells were injected into nude mice, which were randomly divided into two groups. Mice were sacrificed at 5 weeks following inoculation. Tumors were excised from the mice and weighed. (M and N) Stable H1299 cells with HDAC7 knockdown were injected via the tail vein, and the number of visible lung metastases was counted 7 weeks later $(\mathrm{P}=0.0032)$. HDAC, histone deacetylase; CCK-8, Cell Counting Kit-8; Scr, scramble; sh, short hairpin RNA. 

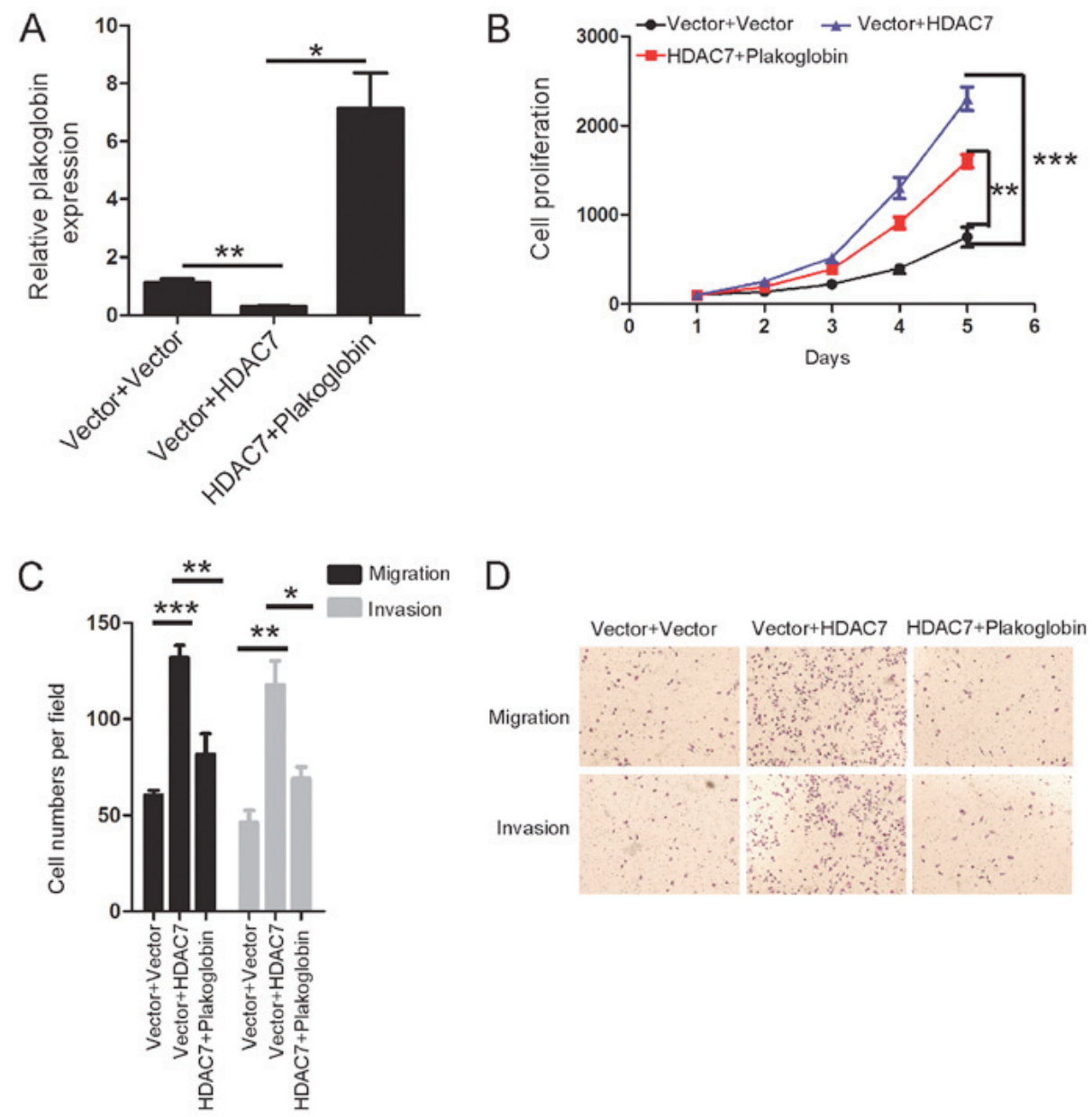

Figure 6. Suppression of plakoglobin by HDAC7 promotes cell proliferation, migration and invasion in A549 cells. (A) mRNA levels of plakoglobin were detected in the indicated cells by reverse transcription-quantitative polymerase chain reaction, with GAPDH as the control. ${ }^{*} \mathrm{P}<0.05$, ${ }^{* *} \mathrm{P}<0.01$. (B) Cell proliferation of the indicated cells in vitro was measured at different time-points, as indicated by a Cell Counting Kit- 8 assay. ${ }^{* *} \mathrm{P}<0.01$, ${ }^{* * * *} \mathrm{P}<0.001$. (C and D) Migration and invasive abilities of the indicated cells were measured at $24 \mathrm{~h}$ by Transwell assays. Panel (D) indicates a representative image. Data are presented as the mean \pm standard deviation. The number of cells passing via the membrane in each cell was statistically analyzed in triplicate and repeated three times with similar results. ${ }^{*} \mathrm{P}<0.05,{ }^{* *} \mathrm{P}<0.01$ and ${ }^{* * *} \mathrm{P}<0.001$. HDAC, histone deacetylase.

invasion compared with the control (Fig. 6B-D). These results indicated that suppression of plakoglobin by HDAC7 promoted cell proliferation, migration and invasion in lung cancer.

\section{Discussion}

Plakoglobin is a structural and functional homolog of $\beta$-catenin (5); these proteins serve two major roles in the cell, including the mediation of cell-cell adhesion and cell signaling (5). As adhesive proteins, plakoglobin and $\beta$-catenin can tether cadherin proteins to the cytoskeleton by interacting with the cytoplasmic domain of cadherins (5). Unlike $\beta$-catenin, plakoglobin has been demonstrated to be absent or weakly expressed in NSCLC cells and tumor tissues (5). Hypermethylation of the plakoglobin promoter mediates repression of its transcription in lung cancer (18); however, the mechanisms that contribute to the inactivation of plakoglobin expression in lung cancer cells have not been fully investigated. The present study aimed to determine which HDACs directly regulate plakoglobin expression in lung cancer cells. The results indicated that HDAC7 could serve as a novel negative regulator of plakoglobin expression in lung cancer.
HDACs $(1,2,5,7$ and 10) are overexpressed in lung cancer and promote lung cancer progression (36-40). HDAC7 promotes the proliferation of cancer cells, including HeLa, HCT116 and MCF-7 cells, which is likely to occur via stimulating c-Myc and inhibiting p21 and p27 expression (41-44); however, HDAC7 depletion had no effect on the proliferation of glioblastoma U87 cells in vitro (45). Therefore, its role in cell proliferation may vary in different cancer cell types and act via different mechanisms. Lei et al (41) reported that HDAC7 has positive effects on lung tumorigenesis in mice and cell proliferation/soft agar colony formation of human lung cancer cell lines by inhibiting signal transducer and activator 3 activation via its deacetylation. The present study also indicated that HDAC7 promoted lung cancer cell proliferation, migration and invasion in vitro, and promoted H1299 cell tumor growth and metastasis in vivo. Mechanistically, it was demonstrated that HDAC7 can directly suppress plakoglobin expression in lung cancer by promoting the deacetylation of $\mathrm{H} 3$ and $\mathrm{H} 4$ histones at the promoter region; a negative correlation between HDAC7 and plakoglobin in lung cancer tissues was reported in the present study. These findings indicate a novel mechanism by which plakoglobin expression is lost in lung cancer cells. 
The results also suggested that HDAC7 promotes lung cancer cell proliferation, migration and invasion, at least partly via inhibiting plakoglobin expression, as demonstrated by rescue experiments. In addition, plakoglobin was identified as a target gene of HDAC in human fibrosarcoma HT1080 cells (26), but the subtype of HDAC was unclear. Therefore, further investigation was conducted in the present study. The novel axis of HDAC7/plakoglobin may provide a basis for the development of novel therapeutic strategies for human lung cancer in the future.

To the best of our knowledge, this study is the first to demonstrate plakoglobin is a target of HDAC7. It was also demonstrated that plakoglobin inhibits HDAC7-mediated lung tumor growth and metastasis, and this axis may be applied in the development of novel therapeutic strategies for treating patients with lung cancer.

\section{Acknowledgements}

Not applicable.

\section{Funding}

This study was supported by the National Science Foundation of China (grant no. 81660449 to YS; grant nos. 81460430 and 81760545 to SWL; grant no. 81372244 to YL) the Jiangxi Provincial Natural Science Foundation of China (grant no. 20161ACB21001 to YS; grant no. 20171BCD40026 to YS), the Jiangxi Provincial Health and Family Planning Commission Foundation (grant nos. 20164005 and 2015A077 to YS) and the Guangxi Natural Science Foundation of China (grant no. 2016GXNS FDA380037 to SWL).

\section{Availability of data and materials}

The datasets used and/or analyzed during the current study are available from the corresponding author on reasonable request.

\section{Authors' contributions}

YS, YL and SWL made substantial contributions to the conception and design of the present the study. YS LS, YW and WY developed the methodology, and acquired, analyzed and interpreted the data. YL and SWL wrote and reviewed the manuscript. SWL supervised the study. All authors read and approved the final version of the manuscript.

\section{Ethics approval and consent to participate}

The present study was approved by the Research Animal Resource Center and the Ethical Committee of Sun Yat-Sen University. Informed consent was obtained from patients.

\section{Patient consent for publication}

Not applicable.

\section{Competing interests}

The authors declare that they have no competing interests.

\section{References}

1. Best MG and Sol N: In't Veld SG, Vancura A, Muller M, Niemeijer AN, Fejes AV, Tjon Kon Fat LA, Huis In't Veld AE, Leurs C, et al: Swarm intelligence-enhanced detection of nonsmall-cell lung cancer using tumor-educated platelets. Cancer Cell 32: 238-252 e239, 2017.

2. Serresi M, Gargiulo G, Proost N, Siteur B, Cesaroni M, Koppens M, Xie H, Sutherland KD, Hulsman D, Citterio E, et al: Polycomb repressive complex 2 is a barrier to KRAS-driven inflammation and epithelial-mesenchymal transition in non-small-cell lung cancer. Cancer Cell 29: 17-31, 2016.

3. Lv XB, Liu L, Cheng C, Yu B, Xiong L, Hu K, Tang J, Zeng L and Sang Y: SUN2 exerts tumor suppressor functions by suppressing the Warburg effect in lung cancer. Sci Rep 5: 17940, 2015.

4. Politi K, Ayeni D and Lynch T: The next wave of EGFR tyrosine kinase inhibitors enter the clinic. Cancer Cell 27: 751-753, 2015.

5. Aktary Z and Pasdar M: Plakoglobin: Role in tumorigenesis and metastasis. Int J Cell Biol 2012: 189521, 2012.

6. Sechler M, Borowicz S, Van Scoyk M, Avasarala S, Zerayesus S, Edwards MG, Kumar Karuppusamy Rathinam M, Zhao X, Wu PY, Tang K, et al: Novel role for $\gamma$-catenin in the regulation of cancer cell migration via the induction of hepatocyte growth factor activator inhibitor type-1 (HAI-1). J Biol Chem 290: 15610-15620, 2015.

7. McCrea PD, Turck CW and Gumbiner B: A homolog of the armadillo protein in Drosophila (plakoglobin) associated with E-cadherin. Science 254: 1359-1361, 1991.

8. Passlick B, Pantel K, Stosiek P, Hosch S, Thetter O and Izbicki JR: Expression of plakoglobin in bronchial carcinomas: Incidence and significance for disease outcome. Langenbecks Arch Chir Suppl Kongressbd 113: 810-813, 1996 (In German).

9. Pantel K, Passlick B, Vogt J, Stosiek P, Angstwurm M, Seen-Hibler R, Häussinger K, Thetter O, Izbicki JR and Riethmüller G: Reduced expression of plakoglobin indicates an unfavorable prognosis in subsets of patients with non-small-cell lung cancer. J Clin Oncol 16: 1407-1413, 1998.

10. Pirinen RT, Hirvikoski P, Johansson RT, Hollmén S and Kosma VM: Reduced expression of alpha-catenin, beta-catenin, and gamma-catenin is associated with high cell proliferative activity and poor differentiation in non-small cell lung cancer. J Clin Pathol 54: 391-395, 2001.

11. He X, Zhou T, Yang G, Fang W, Li Z, Zhan J, Zhao Y, Cheng Z, Huang Y, Zhao H, et al: The expression of plakoglobin is a potential prognostic biomarker for patients with surgically resected lung adenocarcinoma. Oncotarget 7: 15274-15287, 2016.

12. Alaee M, Nool K and Pasdar M: Plakoglobin restores tumor suppressor activity of $\mathrm{p} 53 \mathrm{R} 175 \mathrm{H}$ mutant by sequestering the oncogenic potential of $\beta$-catenin. Cancer Sci 109: 1876-1888, 2018.

13. Winn RA and Heasley LE: Gamma-catenin expression is reduced or absent in a subset of human non-small cell lung cancers, and its re-expression inhibits cell growth. Chest 125 (Suppl 5): 122S-123S, 2004.

14. Winn RA, Bremnes RM, Bemis L, Franklin WA, Miller YE, Cool C and Heasley LE: gamma-Catenin expression is reduced or absent in a subset of human lung cancers and re-expression inhibits transformed cell growth. Oncogene 21: 7497-7506, 2002.

15. Parker HR, Li Z, Sheinin H, Lauzon G and Pasdar M: Plakoglobin induces desmosome formation and epidermoid phenotype in $\mathrm{N}$-cadherin-expressing squamous carcinoma cells deficient in plakoglobin and E-cadherin. Cell Motil Cytoskeleton 40: 87-100, 1998.

16. Breault JE, Shiina H, Igawa M, Ribeiro-Filho LA, Deguchi M, Enokida H, Urakami S, Terashima M, Nakagawa $M$, Kane CJ et al: Methylation of the gamma-catenin gene is associated with poor prognosis of renal cell carcinoma. Clin Cancer Res 11: 557-564, 2005.

17. Shiina H, Breault JE, Basset WW, Enokida H, Urakami S, Li LC, Okino ST, Deguchi M, Kaneuchi M, Terashima M, et al: Functional loss of the gamma-catenin gene through epigenetic and genetic pathways in human prostate cancer. Cancer Res 65: 2130-2138, 2005.

18. Gastaldi T, Bonvini P, Sartori F, Marrone A, Iolascon A and Rosolen A: Plakoglobin is differentially expressed in alveolar and embryonal rhabdomyosarcoma and is regulated by DNA methylation and histone acetylation. Carcinogenesis 27: 1758-1767, 2006 
19. Shafiei F, Rahnama F, Pawella L, Mitchell MD, Gluckman PD and Lobie PE: DNMT3A and DNMT3B mediate autocrine hGH repression of plakoglobin gene transcription and consequent phenotypic conversion of mammary carcinoma cells. Oncogene 27: 2602-2612, 2008.

20. Wang L, Syn NL, Subhash VV, Any Y, Thuya WL, Cheow ES, Kong L, Yu F, Peethala PC, Wong AL, et al: Pan-HDAC inhibition by panobinostat mediates chemosensitization to carboplatin in non-small cell lung cancer via attenuation of EGFR signaling. Cancer Lett 417: 152-160, 2018.

21. Li F, Wang T, Wang Z, Chen X and Liu R: Histone deacetylase inhibitor quisinostat activates caspase signaling and upregulates p53 acetylation to inhibit the proliferation of HepG2 cells. Mo Med Rep 16: 6094-6101, 2017

22. Yu W, Lu W, Chen G, Cheng F, Su H, Chen Y, Liu M and Pang X: Inhibition of histone deacetylases sensitizes EGF receptor-TK inhibitor-resistant non-small-cell lung cancer cells to erlotinib in vitro and in vivo. Br J Pharmacol 174: 3608-3622, 2017.

23. Farooqi AA, Naqvi SK, Perk AA, Yanar O, Tabassum S, Ahmad MS, Mansoor Q, Ashry MS, Ismail M, Naoum GE, et al: Natural agents-mediated targeting of histone deacetylases. Arch Immunol Ther Exp (Warsz) 66: 31-44, 2018.

24. Yim JH, Baek JH, Lee CW, Kim MJ, Yun HS, Hong EH, Lee SJ, Park JK, Um HD and Hwang SG: Identification of HDAC4 as a target of $\gamma$-catenin that regulates the oncogenic K-Ras-mediated malignant phenotype of Rat 2 cells. Biochem Biophys Res Commun 436: 436-442, 2013.

25. Bailey CK, Mittal MK, Misra S and Chaudhuri G: High motility of triple-negative breast cancer cells is due to repression of plakoglobin gene by metastasis modulator protein SLUG. J Biol Chem 287: 19472-19486, 2012.

26. Shim JS, Kim DH and Kwon HJ: Plakoglobin is a new target gene of histone deacetylase in human fibrosarcoma HT1080 cells. Oncogene 23: 1704-1711, 2004.

27. Sang Y, Zang R, Sun L, Kaddie C, Li SW, Xiong L, Peng Y, Zeng L and Huang G: MORF4L1 suppresses cell proliferation, migration and invasion by increasing p21 and E-cadhering expression in nasopharyngeal carcinoma. Oncol Lett 17: 294-302, 2019.

28. Livak KJ and Schmittgen TD: Analysis of relative gene expression data using real-time quantitative PCR and the 2(-Delta Delta C(T)) method. Methods 25: 402-408, 2001.

29. Sang Y, Chen MY, Luo D, Zhang RH, Wang L, Li M, Luo R, Qian CN, Shao JY, Zeng YX, et al: TEL2 suppresses metastasis by down-regulating SERPINE1 in nasopharyngeal carcinoma. Oncotarget 6: 29240-29253, 2015.

30. Győrffy B, Surowiak P, Budczies J and Lánczky A: Online survival analysis software to assess the prognostic value of biomarkers using transcriptomic data in non-small-cell lung cancer. PLoS One 8: e82241, 2013

31. Ding S, Khoury-Hanold W, Iwasaki A and Robek MD: Epigenetic reprogramming of the type III interferon response potentiates antiviral activity and suppresses tumor growth. PLoS Biol 12 e1001758, 2014

32. Vanhaecke T, Papeleu P, Elaut G and Rogiers V: Trichostatin A-like hydroxamate histone deacetylase inhibitors as therapeutic agents: Toxicological point of view. Curr Med Chem 11: 1629-1643, 2004.
33. Lee BM and Mahadevan LC: Stability of histone modifications across mammalian genomes: Implications for 'epigenetic' marking. J Cell Biochem 108: 22-34, 2009.

34. Hayashi-Takanaka Y, Maehara K, Harada A, Umehara T, Yokoyama S, Obuse C, Ohkawa Y, Nozaki N and Kimura H: Distribution of histone $\mathrm{H} 4$ modifications as revealed by a panel of specific monoclonal antibodies. Chromosome Res 23: 753-766, 2015.

35. Huang WY, Hsu SD, Huang HY, Sun YM, Chou CH, Weng SL and Huang HD: MethHC: A database of DNA methylation and gene expression in human cancer. Nucleic Acids Res 43: D856-D861, 2015.

36. Ouaïssi M, Sielezneff I, Silvestre R, Sastre B, Bernard JP, Lafontaine JS, Payan MJ, Dahan L, Pirrò N, Seitz JF, et al: High histone deacetylase 7 (HDAC7) expression is significantly associated with adenocarcinomas of the pancreas. Ann Surg Oncol 15: 2318-2328, 2008.

37. Zhang L, Bu L, Hu J, Xu Z, Ruan L, Fang Y and Wang P: HDAC knockdown inhibits invasion and induces apoptosis in non-small cell lung cancer cells. Biol Chem 399: 603-610, 2018.

38. Jung KH, Noh JH, Kim JK, Eun JW, Bae HJ, Xie HJ, Chang YG, Kim MG, Park H, Lee JY, et al: HDAC2 overexpression confers oncogenic potential to human lung cancer cells by deregulating expression of apoptosis and cell cycle proteins. J Cell Biochem 113: 2167-2177, 2012.

39. Liu C, Lv D, Li M, Zhang X, Sun G, Bai Y and Chang D Hypermethylation of miRNA-589 promoter leads to upregulation of HDAC5 which promotes malignancy in non-small cell lung cancer. Int J Oncol 50: 2079-2090, 2017.

40. Yang Y, Huang Y, Wang Z, Wang HT, Duan B, Ye D, Wang C, Jing R, Leng Y, Xi J, et al: HDAC10 promotes lung cancer proliferation via AKT phosphorylation. Oncotarget 7: 59388-59401, 2016.

41. Lei Y, Liu L, Zhang S, Guo S, Li X, Wang J, Su B, Fang Y, Chen $\mathrm{X}, \mathrm{Ke} \mathrm{H}$, et al: Hdac7 promotes lung tumorigenesis by inhibiting Stat3 activation. Mol Cancer 16: 170, 2017.

42. Gao S, Liu H, Hou S, Wu L, Yang Z, Shen J, Zhou L, Zheng SS and Jiang B: MiR-489 suppresses tumor growth and invasion by targeting HDAC7 in colorectal cancer. Clin Transl Oncol 20: 703-712, 2018

43. Wu MY, Fu J, Xiao X, Wu J and Wu RC: MiR-34a regulates therapy resistance by targeting HDAC1 and HDAC7 in breast cancer. Cancer Lett 354: 311-319, 2014.

44. Zhu C, Chen Q, Xie Z, Ai J, Tong L, Ding J and Geng M: The role of histone deacetylase 7 (HDAC7) in cancer cell proliferation: Regulation on c-Myc. J Mol Med (Berl) 89: 279-289, 2011.

45. Peixoto P, Blomme A, Costanza B, Ronca R, Rezzola S, Palacios AP, Schoysman L, Boutry S, Goffart N, Peulen O, et al: HDAC7 inhibition resets STAT3 tumorigenic activity in human glioblastoma independently of EGFR and PTEN: New opportunities for selected targeted therapies. Oncogene 35: 4481-4494, 2016. 